\title{
O sentido do trabalho do docente universitário: reflexões para o pós-pandemia à luz do pensamento de Viktor Frankl
}

The work meaning of the university professor: reflections for the post-pandemic in the light of the Viktor Frankl thought

El significado del trabajo del profesor universitario: reflexiones para la pospandémica a la luz del pensamiento de Viktor Frankl

Flávio Luiz Honorato da Silva

ORCID: https://orcid.org/0000-0003-1307-3324 Universidade Federal da Paraíba, Brasil E-mail: flavioluizh@yahoo.com.br

Raisa Fernandes Mariz Simões

ORCID: https://orcid.org/0000-0003-0964-9407 Universidade Estadual da Paraíba, Brasil E-mail: raisamariz@gmail.com

Rouseane da Silva Paula Queiroz ORCID: https://orcid.org/0000-0003-3648-146X Universidade do Estado do Rio Grande do Norte, Brasil E-mail: rouseanepaula@uern.br

Alisson de Meneses Pontes

ORCID: https://orcid.org/0000-0003-1751-8394 UNILIFE, Brasil

E-mail: alissonedebora@hotmail.com

\begin{abstract}
Resumo
O docente exerce diversas funções na universidade, a exemplo da pesquisa, ensino e extensão, e isto pode gerar uma sobrecarga física e mental. Eles devem guiar-se e orientar os alunos para uma tarefa a ser realizada, um valor, um sentido a buscar, e, como consequência, encontrar a realização de vida (autorrealização) suas e dos alunos. O objetivo deste estudo foi, portanto, refletir sobre o a vocação/missão do trabalho do docente universitário à luz da Logoterapia $\mathrm{e}$ Análise Existencial, propondo caminhos para lidar com o ensino-aprendizagem e a relação com o aluno no período do pós-pandemia. Utilizou-se de pesquisa bibliográfica em livros e artigos em bases de dados. Constatou-se que o docente que encontra sua missão exercendo a docência e desenvolvendo nela seus valores criativos, mesmo com todos os obstáculos e sobrecargas de ordem física e mental, é capaz de, na sua dimensão noética, autotranscender e chamar outros à autotranscendência, atuando como condutor que orienta ao sentido, principalmente nas situações que exigem uma ressignificação. No pós-pandemia certamente haverá um novo educar, e o professor e aluno devem acolher-se mutualmente nas diversas demandas que serão consequências deste período, buscando mais que uma transmissão do conhecimento, mas principalmente um encontro existencial.
\end{abstract}

Palavras-chave: Sentido do trabalho; Educação; Autotranscendência; Pandemia; Ensino.

\begin{abstract}
The professor performs several functions at the university, an example of research, teaching and extension, and this can generate physical and mental overload. They must guide themselves and guide students towards a task to be performed, a value, a sense to seek, and, therefore, find the realization of life (self-realization) for themselves and their students. The aim of this study was, therefore, to reflect on the vocation / mission of the university professor's work in the light of Logotherapy and Existential Analysis, proposing ways to deal with teaching-learning and the relationship with the student in the post-pandemic period. Bibliographic research in books and articles in databases was used. It was found that the teacher who finds his mission by exercising teaching and developing his creative values, even with all the objectives and overloads of physical and mental order, is capable of, in its noetic dimension, self-transcending and calling others to self-transcendence, acting as a driver that guides the meaning, mainly in the consequences that a reframing. In the post-pandemic there will be a new education, and the teacher and student must accept each other in the diverse demands that will result from this period, seeking more than a transmission of knowledge, but mainly an existential encounter.
\end{abstract}

Keywords: Meaning of work; Education; Self-transcendence; Pandemic; Teaching. 


\section{Resumen}

El docente desempeña varias funciones en la universidad, como investigación, docencia y extensión, y esto puede generar sobrecarga física y mental. Deben orientarse y orientar a los alumnos hacia una tarea a realizar, un valor, un sentido a buscar y, en consecuencia, encontrar la realización de la vida (autorrealización) para ellos y sus alumnos. El objetivo de este estudio fue, por tanto, reflexionar sobre la vocación / misión del trabajo del docente universitario a la luz de la Logoterapia y el Análisis Existencial, proponiendo formas de abordar la enseñanza-aprendizaje y la relación con el alumno en el período pospandémico. Se utilizó la investigación bibliográfica en libros y artículos en bases de datos. Se constató que el maestro que encuentra su misión ejercitando la enseñanza y desarrollando en ella sus valores creativos, aun con todos los obstáculos y sobrecargas del orden físico y mental, es capaz, en su dimensión noética, de auto-trascender y llamar otros a la autotrascendencia, actuando como un conductor que guía el significado, especialmente en situaciones que requieren un nuevo significado. En la pospandémica seguramente habrá una nueva educación, y docente y alumno deberán aceptarse en las diversas demandas que serán consecuencia de este período, buscando más que una transmisión de conocimientos, pero principalmente un encuentro existencial.

Palabras clave: Significado del trabajo; Educación; Autotrascendencia; Pandemia; Ensenãnza.

\section{Introdução}

O docente das universidades, principalmente, públicas do Brasil (federais, estaduais, municipais, institutos federaisIFs) têm em suas atribuições, oficialmente, as funções indissociáveis de ensino, pesquisa e extensão. Há uma quarta função que está interligada entre as acima mencionadas que é a gestão (reitoria, pós-reitorias, direção de faculdade, unidades administrativas ou de centros, coordenações de cursos, entre outras funções administrativas).

Cabe ao professor desempenhar outros papéis, além do ofício de ensinar, no contexto do Ensino Superior, como o papel de orientador, no que tange à pesquisa, e o papel de gestor, no que diz respeito às funções administrativas.

Apesar da sociedade, em geral, compreender o docente como apenas ministrador de aulas, seja na graduação ou na pós-graduação, há, além disso, por exemplo, a tarefa de orientar alunos em pesquisas, estágios, trabalhos de conclusão de curso e afins. Comumente nas questões que envolvem o professor universitário estão as preocupações com a sua didática, portanto, relativas ao campo de ensino-aprendizagem.

Estas diversas atividades docentes acarretam, muitas vezes, a sobrecarga física e mental que podem interferir na vida do professor. Mas, então, por que o caminho da docência? Para responder esta questão é importante compreender o trabalho docente como um todo, para além da profissão.

Para Viktor Emil Frankl, psiquiatra austríaco que desenvolveu a Logoterapia e Análise Existencial, o mais importante não é a profissão em que a pessoa está inserida e a atividade que realiza nesse trabalho, mas a razão pela qual exerce sua profissão e ação. Essa ação deve estar diretamente ligada às escolhas que se faz perante as possibilidades de realização que são apresentadas, ou seja, da capacidade de tomar consciência dos valores que estão postos em cada situação e, a partir daí, adotando uma atitude positiva e criativa perante a vida, é possível realizar na existência o seu caráter único e insubstituível, adquirindo o pleno sentido de sua tarefa (Frankl, 2019).

O sentido do trabalho para a logoterapia é entendido como "dependente antes do ser humano que exerce o trabalho do que da profissão. É ele que imprimirá ao seu mister um caráter de algo único e irrepetível” (JESUS, 2018, 45). A profissão de docente universitário ou qualquer outra, de acordo com o pensamento de Frankl, apresenta no seu labutar diário contínuas oportunidades para a sua realização plena por intermédio da unicidade das tarefas realizadas (obra profissional).

De acordo com Gil (2018) pode-se considerar que a efetiva prática do professor universitário repousa sobre um tripé que envolve os conhecimentos específicos relacionados à matéria, a suas habilidades pedagógicas e à sua motivação.

O que importa primariamente na atuação do profissional docente é mais que o ensinar, o pesquisar, o fazer extensão, o administrar: é transcender o que há de puramente docente, avançando no que é a pessoa humana (o pessoal), vivendo a profissão com sentido e elevando-a ao respeito do que se tem de mais humano no outro, a dignidade de pessoa. Desta forma, o docente se torna um profissional único e insubstituível no que faz. O que defende e acredita como profissional deve também 
não só ser divulgado a partir do seu ensinar, como também do seu viver. A sua prática deve conduzi-lo para seus ensinamentos (Silveira, 2012).

Segundo Frankl (2019) só a partir do momento em que se movimenta-se para além das fronteiras dos princípios puramente profissionais, para além do que está regulado pela profissão, só a partir desse momento é que inicia um trabalho verdadeiramente pessoal, que só ele pode conduzir inteiramente. No trabalho docente, assim como em qualquer outra profissão, há diversas possibilidades de realização, a exemplo da relação com os discentes, com os colegas de profissão ou, em geral, com a comunidade universitária, o que pode favorecer significativamente o encontro de sentido na atuação profissional. Frankl (2019) afirma que o caráter único e irrepetível da pessoa docente, está diretamente ligado à maneira responsável com que exerce sua liberdade, portanto, não está necessariamente ligado ao que faz, mas a razão pela qual faz, a uma resposta consciente ao chamado que a vida lhe faz no aqui-e-agora.

A Logoterapia e Análise Existencial mostra que não se trata de perguntar pelo sentido da vida, da profissão, da tarefa, mas de responder à vida que pergunta sempre. Essa resposta, Frankl afirma que deve ser não com palavras, mas com ações concretas (agir efetivo). Toda a obra de Viktor E. Frankl é uma inspiração antropológica, ou seja, para um mundo que esqueceu o verdadeiro valor do homem, afirmando e reafirmando o resgate primário da dignidade humana.

Sobre esse mundo, Bauman (2007) afirma que a sociedade atual se tornou líquida, reinando a potência, o consumismo, o hedonismo, o imediatismo, a pressa, a eficiência e o consumo. Neste tempo contemporâneo o mundo avançou muito na ciência tecnológica buscando descobertas de novos medicamentos, novos materiais mais ambientalmente sustentáveis, alimentos mais saudáveis (nutracêuticos, probióticos, prebióticos), novos estudos de técnicas pedagógicas e outros avanços. Mas, este mundo, exposto mais ainda, pela pandemia do coronavírus, apresenta que toda esta tecnologia, e pesquisa têm suas limitações. $\mathrm{O}$ mundo que valoriza o jovem, o belo, a imagem, a felicidade e a fama, colocando como fardo o idoso, o ser humano com limitações biopsíquicas, leva, muitas vezes, a um aumento de transtornos como depressão e a ansiedade, podendo levar, em alguns casos, ao suicídio.

Toda esta visão de sociedade líquida de Bauman assemelha-se com a cosmovisão de Frankl de cinco décadas atrás, sugerindo que todo o desenvolvimento tecnológico deve estar a desde a década de 20 do Século XX, a serviço da dignidade humana. Nossa educação do ensino universitário, nossos planejamentos devem estar focados na dignidade do ser humano. Assim, este artigo, utilizando o pensamento de Frankl, por meio de revisão bibliográfica e justificada, teoricamente, na produção de Viktor Frankl e de autores que reconhecem o seu legado na área, busca apresentar a ação motivacional da existência do ser professor universitário nas instituições superiores de ensino, tentando mitigar o estresse da bela profissão, sem querer aqui mostrar uma fantasia, mas uma realidade antropológica: o que é o homem para Frankl, nas dimensões biológica, psicológica e noética ou espiritual - ontologia dimensional (Frankl, 2015), que humaniza as vivências docentes nas suas múltiplas atividades e apresentando, no pensamento frankliano, respostas para ação da docência na pós-pandemia.

\section{Metodologia}

O presente artigo foi organizado a partir de uma revisão da literatura baseado na metodologia de Koche (2011). Foram utilizados os fundamentos teóricos do pensamento de Viktor Emil Frankl, fundador da Logoterapia e Análise existencial que desenvolve a compreensão do tema. Foi utilizada da metodologia qualitativa descritiva reflexiva, com fundamento fenomenológico-existencial na perspectiva da abordagem da Logoterapia por meio de levantamento bibliográfico (Silva et al., 2020, Silva et al., 2021). 


\section{Resultados e Discussão}

Os resultados da pesquisa são apresentados em forma de descrição e análise do material coletado na literatura, por itens.

\subsection{Vocação ou missão?}

Segundo Frankl (2015) toda pessoa tem uma vocação ou missão de vida específica, ou seja, pessoa deve conduzir sua tarefa para a ação concreta na vida. A pessoa é insubstituível na tarefa que deve conduzir. Assim, a tarefa de cada um é única, consiste, portanto numa oportunidade particular de realizar. Frankl utiliza das perguntas sábias do rabino Hillel, escritas há quase dois mil anos para apresentar a importância da pessoa na tarefa da vida do ser humano: "Se eu não o fizer, quem o fará? Se eu não fizer agora mesmo, quando eu deveria fazê-lo? E, se o fizer apenas para mim mesmo, o que serei eu?" (citado por Frankl, 2011, 73). Ou seja, comentando as questões de Hillel, tem-se que o $1^{\circ}$ é o caráter de responsabilidade da existência humana. O $2^{\circ}$ é a transitoriedade da vida e fugacidade das situações e o $3^{\circ}$ é o caráter autotranscendente da existência. Ser humano, é ser em direção a algo ou alguém.

Então, na perspectiva da Logoterapia e Análise Existencial, o sentido pode se expressar por três vias de valores: criativos, aquilo que o ser humano faz pelo mundo como o trabalho ou um voluntariado, praticando um ato para o outro; valores vivenciais ou experienciais, aquilo que a pessoa recebe do mundo experimentando como a arte, a filosofia, o belo, a natureza, a música, o encontro com alguém no amor; e valores atitudinais, a postura assumida diante do sofrimento inevitável (Jesus, 2018). Assim preconiza Frankl (2008, 133): "Não se deve procurar um sentido abstrato da vida. Cada qual tem sua própria vocação ou missão específica na vida; é preciso executar uma tarefa concreta, que está a exigir realização. Nisso a pessoa não pode ser substituída, nem sua vida pode ser repetida. Assim, a tarefa de cada um é tão singular como a sua oportunidade específica de levá-la a cabo.”

Os valores de criação são considerados como aqueles significados com que a pessoa transforma as forças que há no mundo buscando estruturar e planejar ao bem de todos os seres humanos. Criar para o mundo e ser usufruído pelo outro. O trabalho é considerado o valor típico de criação, ou seja, há no ser humano um sentimento de protagonismo da própria vida. Mas, reafirmando o pensamento de Frankl, o central não é a profissão em si, mas a atitude pelo qual o ser humano realiza a sua atividade (Pacciolla, 2015).

De acordo com Pintos (2017), o bem comum não deve ser construído, mas ser permitido. Em outras palavras, é necessário que se ajude a pessoa a compreender a fundamental importância da sua realização e, como consequência inerente, elevar o bem comum na comunidade. Esta é a missão do professor: propor que o bem comum seja realizado pelo educando com compromisso e responsabilidade.

A perspectiva de sentido para a vida no âmbito acadêmico parece ser um tema ultrapassado no Brasil. Entretanto, diversos autores, como Carl Rogers e Paulo Freire, concebem que a escola/universidade desempenha um papel fundamental na vida de seus integrantes, principalmente para professores e alunos, que vai além da simples transmissão ou recepção de conteúdos acadêmicos ou do repasse de tradições, mas, como descreve Frankl $(2011,108)$, essas instituições devem:

Refinar a capacidade humana de encontrar aqueles sentidos únicos que não se deixam afetar pelo declínio dos valores universais. Essa capacidade humana de encontrar o sentido escondido por trás de cada situação singular é o que chamamos de consciência. A educação deve, portanto, guarnecer o homem com os meios para encontrar o sentido. Ora, em vez disso, o que muito se vê é que os sistemas escolares contribuem para o vácuo existencial. O sentimento de vazio e de falta de sentido por parte dos estudantes é reforçado pelo modo reducionista por meio do qual as descobertas científicas lhes são apresentadas. Os alunos são expostos a um processo de doutrinação que mescla os princípios de uma teoria mecanicista do ser humano a uma filosofia de vida relativista. 
De acordo com Moran $(2000,30)$ o docente é um facilitador do aprendizado do aluno. "O professor verdadeiramente comprometido com o seu papel e que procura aliar seu conhecimento teórico à prática profissional atualizada, certamente participará da formação de profissionais competentes, cidadãos atuantes e responsáveis. O professor deve ser um orientador/mediador intelectual que informa, ajuda a escolher as informações mais importantes".

A vocação ou missão do educador é afirmada por Hoz (2018) como a educação que deve se apoiar no valor primário do ser humano (dignidade de pessoa), não considerando como apenas instinto (reage aos estímulos do meio), mas como um ser que investiga e é ativo. Como diz Frankl (2019), as possibilidades representam o caráter concreto de todo "dever-ser" dado ao ser humano, para executar no agora (“dever fazer"), porque todo ser pessoa é único e irrepetível apresentando que cada missão na vida deve se materializar-se pela condição única e irrepetível.

Souza e Gomes (2013), utilizando a perspectiva da Análise Existencial de Frankl e sua visão de pessoa, que compreende o ser humano como uma unidade antropológica aponta que o papel da educação na humanização (educadores) é colocar em prática o "papel fundamental da educação no desenvolvimento dos indivíduos e das sociedades, não só como transmissora de conhecimentos como meio para alcançar um fim, mas como formadora de um ser humano que responda aos seus anseios de profundidade com sentido".

Miguez (2014) apresenta em seus estudos que a educação é um processo que necessita de uma decisão responsável em vista de realizar um projeto ontológico e ético, sendo de vital importância uma vocação pessoal que deve ter como meta ser o que deves ser. Ou seja, o docente universitário deve configurar a sua ação educativa, em todas as tarefas a ser cumpridas (ensino, pesquisa, extensão e administração) na perspectiva de colocar o protagonismo no sujeito (própria existência) e não na coisa ou coisas. Não se tem a ideia de um antropocentrismo, pautado no voltar-se para si (autorrealização), mas considera-se que o sentido está no mundo, e não em nós mesmos.

Nessa perspectiva, concebe-se que não há como desvincular o sentido da educação, bem como das relações interpessoais inerentes a este processo, como a do professor/aluno, pois seria desconsiderar algo intrínseco ao homem, sua própria humanidade. Análogo a isso, Frankl (2011) concebe o homem como sendo responsável diante de sua transitoriedade, pois o tempo limitado de vida o impulsiona a uma ação livre no presente, a dar respostas às questões que a vida lhe apresenta no aqui-e-agora, a tirar lições dos erros passados, dando espaço à possibilidade de desenvolvimento do "dever-ser" futuro, baseadas em uma ação livre e responsável. Portanto, educação e responsabilidade estão relacionadas, pois o conhecimento e o compromisso parecem caminhar juntos. "Mais do que nunca, a educação há de ser a educação para a responsabilidade. Ser responsável é ser seletivo, possuir capacidade para escolher” (Frankl, 1991, 19).

A Logoterapia e Análise Existencial enfatiza que a educação deve ser exercida na liberdade para tomar decisões e realizar escolhas, sendo a liberdade inseparável da responsabilidade. Então o docente deve educar para a responsabilidade mostrando que o desenvolvimento do futuro profissional (aluno) em qualquer área de atuação equivale em desenvolver a capacidade do ser humano em tomar decisões com valores, colocando a dignidade humana como referencial primária.

\subsection{Vontade de prazer, vontade de poder ou vontade de sentido como base da vivência docente?}

$\mathrm{Na}$ academia, em geral, o docente pode conduzir sua profissão buscando sucesso (ser bolsista pesquisador obtendo reconhecimento da classe acadêmica) e/ou poder (ter cargos administrativos elevando o status).

São múltiplos os papeis desempenhados pelo professor universitário, Gil (2018), em sua obra Didática do Ensino Superior, aponta 27 papéis (Quadro 1), e afirma que a profissão docente é bastante complexa visto que implica no desempenho de múltiplos papéis. 
Quadro 1 - Papeis desempenhados pelo docente universitário no Brasil.

\begin{tabular}{|l|l|l|}
\hline Administrador & Didata & Modelo de professor \\
\hline Especialista & Educador & Assessor de estudante \\
\hline Aprendiz & Diagnosticador de necessidade & Facilitador de aprendizagem \\
\hline Membro de equipe & Conferencista & Educador \\
\hline Participante & Modelo profissional & Mentor \\
\hline Avaliador & Preparador de material & Líder \\
\hline Assessor de currículo & Agente de socialização & Elaborador de guias de estudo \\
\hline Instrutor & Animador de grupos & Pesquisador \\
\hline Planejador de disciplina & Conselheiro & Instrutor \\
\hline
\end{tabular}

Fonte: Gil (2018).

Tudo isto são metas salutares para a carreira docente, mas o excesso de autocobrança, da administração universitária e da sociedade, tem aumentado assustadoramente, nos últimos anos, o adoecimento dos educadores. É importante que o docente se preocupe com sua saúde física e mental para poder exercer da melhor forma sua missão de ensinar, orientar e administrar.

Na visão humanística de Frankl, o docente (educador), visto como pessoa, deve primordialmente se confrontar com sua responsabilidade, buscando viver, no seu cotidiano de vida, os valores de criação, de vivência e de atitude (frente ao sofrimento, culpa e morte) ressignificando a prática docente e assim encontrando sentido da vida no trabalho acadêmico.

Frankl (2015) afirma categoricamente que, quanto mais a pessoa busca o prazer, o poder e a felicidade, mais se afasta disto. A Logoterapia e Análise Existencial reforça a vontade de sentido como pressuposto primário para a autossatisfação (autorrealização) da pessoa, utilizando-se da atitude de autotranscendência (atitude de sair de si e dirigir-se a algo ou alguém). Este algo pode ser um trabalho, uma obra, uma missão, uma tarefa, entre outros; já esse outro pode ser um tu (uma outra pessoa) ou um Tu (chamamos de Deus).

A abordagem centrada na pessoa desenvolvida em 1940 pelo psicólogo Carl Rogers apresenta a autorrealização, mas Frankl afirma que a autorrealização do ser humano é uma consequência da autotranscendência. A autotranscendência é a capacidade humana de sair de si e projetar-se para o outro, conduzir-se e ordenar-se a algo ou a alguém: entregar-se o ser humano a uma obra a que se dedica, a uma pessoa que ama, ou a Deus, a quem serve (Frankl, 2015)

Frankl afirma que quando o prazer ou o poder é utilizado pelo ser humano como um fim em si mesmo, ele não atinge o alvo da felicidade, se frustrando e vem o vazio existencial (Aquino, 2013). Assim, os docentes devem guiar-se e orientar os alunos para uma tarefa a ser realizada, um valor, um sentido a buscar, e, como consequência, encontrar a felicidade e realização de vida (autorrealização) suas e dos alunos.

É de vital importância compreender o pensamento de Frankl que propõe uma reflexão mais fenomenológica, tendo base na autocompreensão ontológica pré-reflexiva da existência (Frankl, 2019, 12). Heloísa Reis Marino, no prefácio à segunda edição brasileira do livro "O sofrimento humano: fundamento antropológico da psicoterapia", explica que: 
"Autocompreensão significa que opinião tenho de mim mesmo como pessoa, o que acredito que seja ser um homem. Ontológica quer dizer que se refere à existência humana. E pré-reflexiva significa que, antes de ter alguma ideia do que é a filosofia, a psicologia ou a psiquiatria, já sei de antemão o que é a vida... Portanto refere-se à autocompreensão implícita da existência humana".

Segundo Jesus (2018) Frankl não apresenta uma abordagem moralista, mas apresenta pensamentos ontológico e axiológico que não se reduz a dicotomia do bem e do mal, mas a promoção ou a dificuldade da realização de sentido na vida do ser humano. A ontologia dimensional (biopsíquicoespiritual) baseia toda atenção sobre o ser humano como pessoa, defendendo a dignidade humana, bem diverso dos pensamentos do Individualismo e do Materialismo.

\subsection{Arbeit macht frei (Fake news, uma arma poderosa contra a verdade e o conhecimento)}

Esta famosa frase alemã, traduzida para o português quer dizer "o trabalho liberta", encontra-se na principal entrada do campo de concentração de Auschwitz, onde foram exterminados entre 1,1 e 1,5 milhão de pessoas de 1940-1945, e era uma fake news para os egressos no campo. Talvez por isso Frankl se importe tanto com a verdade, tendo em vista que viveu as mazelas do campo de concentração e suas mentiras. É importante, para o autor, que a verdade seja uma ética disseminada em uma sociedade para o bem da dignidade humana.

Assim, o professor universitário orientado para uma educação do sentido, deve ter uma postura de ação ética e de princípios de valores que a comunidade universitária possa perceber toda ideologia que tenta denegrir este espaço. Nos últimos anos tem-se disseminados notícias falsas do comportamento de docentes e discentes no âmbito do campus universitário, como é bem vinculado na mídia em geral. O objetivo destas falsas notícias é utilizar de um fato bem particular e generalizar, tentando denegrir a imagem de toda comunidade universitária. Os regimes autoritários sempre utilizaram deste expediente de macular uma instituição, uma cultura, uma ideia utilizando de estereótipos.

É preciso ter um senso crítico e de valores para ir de encontro a estas investidas na busca de denegrir a comunidade universitária, em função da preservação da dignidade desta comunidade de grande importância para o desenvolvimento das atuais e futuras gerações deste país. Não é causa de direita ou de esquerda, bem como de ideologias, mas de política de valorização de uma instituição que tem muito a contribuir com o crescimento técnico, humano, da saúde dos brasileiros (estudo de caso aqui se limitando o nosso país).

É uma época difícil em função do que os pesquisadores chamam "pós-verdade" (D’Ancona, 2018), onde, em pleno Século XXI, no ano de 2021, é necessário reafirmar que a terra é redonda e não plana. Segundo D’Ancona (2018) o pluralismo é saudável quando não é superado pelo relativismo que não há certo e errado e não há verdade científica, gerando a sensação atual de que todas as opiniões devem ser aceitas e consideradas igualmente autênticas. Esta pode ser uma missão do educador diante de seus pares e de seus alunos: buscar alertá-los para uma consciência crítica que as teorias conspiratórias devem ter um filtro para tentar ver a diferença de informações contraditórias e duvidosas, para buscar discernir o que é "FAKE NEWS". Na origem da psicologia extremista (seja ideologia de direita ou de esquerda) está sempre a consideração da conspiração externa (teoria da conspiração) (Eco, 2019).

D’Ancona (2018) afirma que hoje se está escolhendo as versões e narrativas de notícias que encaminham para uma segurança emocional e não as que são verdadeiras, contendo interesse ideológico ou crença pessoal. O professor não tem a prerrogativa de ser um moralista e apontar o que é certo e o que é errado com sua visão cultural e ideológica, mas tentar apontar para o discente que o senso crítico tem que ser utilizado com critérios onde a verdade científica e dos fatos seja primazia epistemológica. Frankl (1991) propõe uma autoeducação que liberte o homem dos seus condicionamentos. Este modelo de educação está baseado em uma postura livre, consciente e responsável, isto é, frente a sua liberdade o ser humano em última instância torna-se responsável pela construção do seu ser no mundo. 
D’Ancona $(2018,101)$ utiliza o seguinte jargão acadêmico de pesquisa: diante de tantas informações que se lê e escuta na mídia social, é preciso que a formação dos futuros profissionais (alunos) deva utilizar-se de senso de editores de revistas científicas, filtrando, checando e avaliando com critérios estas informações. Isto é visto, atualmente, pelo sistema de plágio dos trabalhos de muitos alunos, muitas vezes sem conhecimento de estar realizando uma fraude (claro, que não é justificativa para o delito, em função da lei vedar este tipo de conduta). Os desafios são enormes neste tempo de fake news e plágios, então é imperativo que se alerte sobre ética acadêmica e de vida dos alunos, e sobre a importância de não só entender os textos ou falas que recebem, mas também de não plagiar ou enviar estes textos. Segundo D’Ancona $(2018,127)$ : “...se a verdade ainda importa para nós como civilização, não é uma missão da qual poderemos nos esquivar".

Pintos (2017) apresenta um paradigma dos tempos atuais onde diz que "a verdade é o resultado do consenso, do parecer majoritário, o qual decreta por maioria que aquilo que era verdadeiro já não o é e, em sua substituição, estabelecemos uma nova verdade. Ou seja, uma nova ordem, uma nova realidade, uma nova natureza, bastando apenas que muitos a decidam para que assim seja. Uma verdade de consenso". Ele continua afirmando que a verdade apoiada em valores nunca sai de moda, nem é sensível de compreensão do padrão agora deve ser assim, ou agora é assim. É necessário compreender que as teorias científicas não explicam tudo, mas a metodologia científica ajuda muito a civilização moderna em buscar o progresso da humanidade no tocante ao meio ambiente, a saúde, a vida como um todo.

É de grande importância para a formação do aluno a relação entre o aluno e o professor, em que o docente/educador deve ser um condutor de valores, e não somente um intermediador do aprendizado, assim ampliando a visão do seu aluno e ressaltando que toda pessoa humana, neste caso o aluno, se realizará por completo, quando abraçar as necessidades do outro vivendo a autotranscendência. Desta forma, o educador tem a missão de ser intermediário de formador de cidadãos com consciência, fazer-se pessoa da sua própria história que é crítico de ideias que aprisionam o ser humano em ideologias que são formas atuais de escravidão e ignorâncias.

O avanço da tecnologia digital nos trouxe muitas boas comodidades e contatos remotos que ajudaram muito neste tempo de pandemia. Mas, como toda tecnologia, o uso é que a faz proveitosa ou maléfica para a comunidade. A tecnologia não tem moralidade é amoral (não é imoral nem moral), o que se faz dela é que se torna imoral ou moral. O uso sem senso crítico, distraído e sem conferir, compartilhando e endossando as notícias sem este modo de conferir, faz do usuário uma presa fácil, sem resistência e levando-se a estilos de vida que são explicados com simplismo por uma única alegação: agora é assim. A geração do "agora é assim" se satisfaz com a cultura do imediato, o reativo que "é promotora da impulsividade" (Pintos, 2017).

A formação acadêmica do aluno, tendo a intermediação do docente/educador precisa estar implícita em toda aprendizagem, no preparar-se para as frustrações presentes e futuras, pela fragilidade inerente do ser humano (Pintos, 2017).

\subsection{Pós-pandemia (transição para um "novo normal”)}

Não havia nenhuma ideia de que o ano de 2020 seria de mudanças radicais, com a pandemia do coronavírus que veio em escala mundial, afetando a vida social, econômica e psicológica. Os profissionais da área da saúde mental declaram que o pós-pandemia aumentará nas pessoas sintomas de ansiedade, angústias, Transtorno Obsessivo Compulsivo (TOC), transtorno de estresse pós-traumático (TEPT), e não só limitado para pessoas que estiveram em tratamento para recuperação da covid 19, mas para muitos que sofreram com a perda de entes queridos e que sua saúde mental foi afetada pelo isolamento (Medeiros et al., 2020).

Conforme Medeiros et al. (2020) a mudança de atitude frente a vida no isolamento social deve ser seguida no póspandemia, ou seja, refletir, como afirma Frankl, acerca da pergunta sobre o sentido da vida. Ou seja, não se deve esperar que a vida responda, mas que a vida pergunte e que frente a esta pergunta seja respondida pela nossa atitude de ouvir a consciência. A pandemia está gerando consequências sociais, econômicas e políticas que de acordo com Madeiros et al. (2020) o que será 
feito por cada pessoa no pós-pandemia é que pode mudar a sua história, sendo a inspiração assumir com valentia a vida, como um atual caminho de busca de sentido da vida. Os desafios das consequências da pandemia nas áreas sociais, políticas, econômicas solicitará da missão docente na academia a necessidade da consciência do cuidado na dimensão total do ser humano (biopsíquicoespiritual) de acordo com as reflexões de Frankl.

A docência de modo geral, mesmo não sendo formada para trabalhar com saúde mental, na sua missão de educar e orientar para o sentido, acolherá jovens adultos que precisam de referências de educadores desenvolvendo valores atitudinais e dispostos a lidar com o ser humano, com suas limitações físicas e psicológicas advindas do estresse pandêmico e voltados para lidar com o ser humano, sendo uma pessoa com suas limitações psicológicas.

Como isto pode ser executado na missão do docente na pós-pandemia? Na visão da Logoterapia e Análise existencial o sofrimento só tem sentido se quem sofre se transformar para uma pessoa melhor, de valores que permitam contemplar a vida e o outro com empatia. O valor de atitude no sofrimento é uma busca de sentido concreto na vida da pessoa. Jesus (2018) utilizando da visão frankliana diz: "Quando se afirma que o sentido da vida acontece pela realização de valores, não se está propondo algo metafísico ou abstrato, ao contrário, algo muito concreto. O problema do sentido da vida é uma tarefa concreta, que desafia os seres humanos em contextos diferentes da vida, na saúde, no trabalho, nas finanças, nos relacionamentos, na cultura; nos momentos alegres, plenos e sublimes, mas também nos momentos difíceis, complicados e trágicos. Trata-se de uma questão concreta, do ser humano real, e não de uma digressão teorética." (Jesus, 2018, 50).

Para docentes pesquisadores que orientamos alunos de graduação (Iniciação Científica, entre outras orientações), pósgraduação (mestrado e doutorado, especialização de outra natureza) a incumbência é que estes trabalhos sejam divulgados em artigos, capítulos de livros e livros para a publicização das pesquisas para o mundo acadêmico, principalmente neste período de reflexão e produtividade que a pandemia trouxe. Frankl (2010, 9), como grande pesquisador, psiquiatra e neurologista, e doutor em filosofia afirmou: "Escrever um livro não é uma grande coisa, saber viver é muito mais e ainda mais é escrever um livro que ensine a viver. Mas o máximo é viver uma vida sobre a qual se possa escrever um livro". O grande legado de Frankl foi a concretude de suas palavras, ou seja, tudo que disse, escreveu e viveu na sua vida. "Se poderia dizer: "No princípio era o Sentido, e o Sentido era a Ação". Não respondemos à vida com palavras, mas com ações. Sim, ações das quais nos tornamos responsáveis"

Diante de todo o exposto, percebe-se que os docentes estão expostos a muitas pressões na vida acadêmica. $\mathrm{O}$ estresse docente é marcado pelas experiências com frustrações, tensões desagradáveis, tendo como consequência uma missão de um professor com abatimento no dia a dia, muitas vezes gerando ansiedade, acompanhada ou não da depressão.

Pensando nisso, desenvolveu-se seis itens que podem ajudar a docência ser uma missão de vida que realize o sentido, sem esquecer os aspectos socioeconômicos como melhor remuneração do trabalho, maior respeito da sociedade com esta profissão de vital importância para o futuro do mundo pós-pandemia. Seguindo adaptações, que de acordo com González (1997) faz crescer o ser docente como pessoa fiel a sua vocação de educador, eis os pontos:

I) entregar-se com amor e vida a uma tarefa em que se acredita;

II) realizar a tarefa observando que se constrói algo que tenha sentido para os outros;

III) sentir-se que a profissão de docente cumula de satisfação, tendo como consequência a felicidade da realização;

IV) verificar que a tarefa realizada ajuda com a sociedade ou comunidade em geral como um artigo, um livro, um cidadão de bem formado (graduado com qualidade);

V) observar que sua missão ajuda na formação cidadã e aguça o sentido de vida nos seus alunos; 
VI) saborear a alegria do esforço cotidiano de ser fiel a sua missão de educador e se for uma pessoa crente, acreditar que tem um Ser que nos ama incondicionalmente. Para os não crentes, ter o prazer de uma consciência satisfeita do trabalho.

Em todos esses aspectos apresentam a dimensão humana da missão de educar, podendo ser um precioso antídoto contra a frustração existencial da profissão docente.

É importante como educador apresentar a seus pares e aos educandos um juízo da vida humana recheado de significados de cada situação com que se produz a vida diária. Essa habilidade tem um nome: consciência. A consciência conduz o ser homem a cada momento de sua caminhada no dia a dia, apontando o que deve ser feito, o ser que deve ser. $\mathrm{O}$ desenvolvimento da consciência do ser humano é primordial para o amadurecimento da pessoa educada, apurada e de senso crítico, e atinge o entendimento dos significados de cada situação e decide em valores (Fizzote, 1996).

O educador em sua missão de trabalho deve utilizar a tecnologia e alertar a sua utilização não como fim, mas como meio de alcançar uma compreensão do fenômeno. Realizar orientação para valores (sentido da vida) é um fator protetor e profilático para a vida. Todo ser humano deve ter direito a uma vida com sentido (valor de sobrevivência) como direito inalienavelmente humano.

\section{Considerações Finais}

Miguez (2014) aponta, na direção do pensamento frankliano, que nesta época de despersonalização e de desumanização, o vazio existencial é consequência do sentimento de falta de sentido, se revelando na sensação de uma ilógica existência, apresentando sintomas de tédio, falta de esperança no presente e futuro de sua vida, em geral, levando ao desespero. Então, a busca de sentidos e de valores mobiliza o ser humano a ação no dia a dia para se distanciar do desespero.

Antes da pandemia estávamos vivendo numa época em que o sentimento de vazio se alastrava como um vírus. Após esse período, certamente haverá um aumento nos sentimentos de ansiedade e angústia das pessoas. O fato certo é que todos retornarão às suas atividades, mas, sabendo que a forma como cada um lidou com o estresse da pandemia foi única, com suas motivações que levaram a desistir ou continuar com suas tarefas. Incerta será a forma como cada pessoa voltará a vivenciar o seu cotidiano. Assim, é de vital importância que os educadores/professores tenham paciência consigo mesmo, pois estarão também ressignificando o novo educar, e com os alunos, procurando acolher situações diversas vivenciadas, não se preocupando somente com a transmissão do conhecimento de sua disciplina ou de sua área, mas concomitantemente, com sua experiência de vida, tentando aguçar a consciência do aluno para que ele possa buscar o sentido na vida e se imunizar do vazio existencial. Ao contrário das fontes limitadas de energia, o sentido é inesgotável em qualquer momento da vida (FRANKL, 2015), sendo, portanto, possível de ser (re)encontrado mesmo diante das mais adversas situações imutáveis.

Sendo assim, a visão que tem a Logoterapia e Análise Existencial é que o docente ao encontrar sua missão exercendo a docência e desenvolvendo nela seus valores criativos, mesmo com todos os obstáculos e sobrecargas de ordem física e mental, é capaz de, na sua dimensão noética, autotranscender e chamar outros à autotranscendência, atuando como condutor que orienta ao sentido, pois, segundo Frankl, nada proporciona uma melhor capacidade de superação e resistência aos problemas e dificuldades em geral do que a consciência de ter uma missão a cumprir na vida. A necessidade básica de sentido é fundamental para a questão urgente da falta de sentido, do desespero, do suicídio, do mal-estar da vida.

\section{Contribuições para trabalhos futuros}

A questão nesse artigo busca apresentar o educador na sua missão que pode e deve ajudar seus alunos no primário e crucial anseio humano de encontrar um sentido para suas vidas. Assim, não apenas os educandos poderão encontrar sentido para sua vida por meio do educador, mas este também poderá transformar sua prática docente de uma profissão para uma 
missão. Em trabalhos futuros estudar o impacto da visão de missão na perspectiva da Logoterapia no impacto da saúde mental e sentido de vida da docência universitária, em estudo de caso com professores da tecnologia.

\section{Referências}

Aquino, T. A. A. (2013). Logoterapia e análise existencial: uma introdução ao pensamento de Viktor Frankl. Editora Paulus.

Bauman, Z. (2007). Tempos líquidos Jorge Zahar Ed.

D’Ancona, M. (2018). Pós-verdade. Faro Editora.

Eco, U. (2019). O fascismo eterno. (3a ed.), Record.

Fizzote, E. (1996). Conquista da liberdade: proposta da logoterapia de Viktor Frankl. Ed. Paulus.

Frankl, V. E. (1991). A psicoterapia na prática. Papirus.

Frankl, V. E. (2008). Em busca de sentido. Um psicólogo no campo de concentração. (33a ed.), Ed. Sinodal; Ed. Vozes.

Frankl, V. E. (2010). O que não está escrito nos meus livros: memórias. Ed. É Realizações.

Frankl, V. E. (2011). A vontade de sentido: fundamentos e aplicações da logoterapia. Ed. Paulus.

Frankl, V. E. (2015). O sofrimento de uma vida sem sentido: caminhos para encontrar a razão de viver. Ed. É Realizações.

Frankl, V. E. (2019). A psicoterapia na prática. Ed. Vozes.

Gil, A. C. (2018). Didática do ensino superior. (2a ed.), Ed. Atlas.

González, S. R. (1997). Crescer como pessoa: etapas e obstáculos. Ed. Paulus.

Hoz, V. G. (2018). Educação personalizada. CEDET.

Koche, J. C. (2011). Fundamentos de metodologia cientifica. Vozes. http://www.brunovivas.com/wp-content/uploads/sites/10/2 018/07/K\%C3\%B6cheJos\%C3\%A9-Carlos0D0AFundamentos-de-metodologia-cient\%C3\%ADfica-_-teoria-da0D0Aci\%C3\%AAncia-einicia\%C3\%A7\%C3\%A3o-\%C3\%A0pesquisa.pdf.

Jesus, L. M. (2018). Qual é o sentido? reflexões sobre o sentido da vida a partir de Viktor Frankl. EDIPUCRS.

Medeiros, A. Y. B. V., Pereira, E. R., Silva, R. M. C. R. A., Dias, F. A. (2020). Fases psicológicas e sentido da vida em tempos de isolamento social por pandemia COVID-19 uma reflexão a luz de Viktor Frankl. Research, Society and Development, 9(5). http://dx.doi.org/10.33448/rsd-v9i5.3131.

Miguez, E. M. (2014). Educação em busca de sentido: pedagogia inspirada em Viktor Frankl. Ed.Paulus.

Moran, J. M. (2000). Ensino e aprendizagem inovadores com tecnologias audiovisuais e telemáticas. Papirus.

Pacciolla, A. (2015). Psicologia contemporânea e Viktor Frankl: Fundamentos para uma psicoterapia existencial. Editora Cidade Nova.

Pintos, C. G. (2017). O mar me contou. A logoterapia aplicada ao dia a dia. Editora Cidade Nova.

Silva, F. L. H.; Assis, M. D.; Durand, T. P.; Santos, E. N. M.; Honorato, M. C. M., \& Pontes, A. de M. (2020). Envelhecimento e sentido da vida na perspectiva de Viktor E. Frankl. Research, Society and Development, 9(11), e38591110068, 10.33448/rsd-v9i11.10068.

Silva, F. L. H.; Assis, M. D. de; Honorato, M. C. M.; \& Pontes, A. de M. (2021). Educação tecnológica e em valores na perspectiva de Viktor Frankl. Research, Society and Development, 10 (1), e23910111690, 10.33448/rsd-v10i1.11690.

Silveira, M. L. (2020). Há coerência entre a vida e a obra de Viktor Frankl? Logos \& Existência: Revista da Associação Brasileira de Logoterapia e Análise Existencial, 1(2).

Souza, E. A., Gomes, E. S. (2014). Educação, um processo de humanização na visão frankliana. Foro de Educación, 11(15). http://dx.doi.org/10.14516/fde.2013.011.015.010. 